\title{
Resilience of Biocontrol for Aflatoxin Minimization Strategies: Climate Change Abiotic Factors May Affect Control in Non-GM and GM-Maize Cultivars
}

\section{Alessandra Marcon Gasperini, Alicia Rodriguez-Sixtos, Carol Verheecke-Vaessen, Esther Garcia-Cela, Angel Medina and Naresh Magan*}

Applied Mycology Group, Cranfield Soil and Agrifood Institute, Environment and Agrifood Theme, Cranfield University, Bedford, United Kingdom

There has been significant interest in the development of formulations of non-toxigenic strains of Aspergillus flavus for control of toxigenic strains to reduce the aflatoxin $\mathrm{B}_{1}\left(\mathrm{AFB}_{1}\right)$ contamination of maize. In the future, climate change $(\mathrm{CC})$ abiotic conditions of temperature $\left(+2-4^{\circ} \mathrm{C}\right), \mathrm{CO}_{2}$ (existing levels of 400 vs. 800-1,200 ppb), and drought stress will impact on the agronomy and control of pests and diseases. This study has examined (1) the effect of two-way interacting factors of water activity $\times$ temperature on colonization and $\mathrm{AFB}_{1}$ contamination of maize cobs of different ripening ages; (2) the effect of non-toxigenic strains of $A$. flavus (50:50 inoculum ratio) on relative control of toxigenic $A$. flavus and $\mathrm{AFB}_{1}$ contamination of ripening cobs; (3) post-harvest control of $\mathrm{AFB}_{1}$ by non-toxigenic strains of $A$. flavus in non-GM and isogenic $\mathrm{GM}$ maize cultivars using the same inoculum ratio; and (4) the impact of three-way interacting CC factors on relative control of $\mathrm{AFB}_{1}$ in maize cobs pre-harvest and in stored non-GM/GM cultivars. Pre-harvest colonization and $\mathrm{AFB}_{1}$ production by a toxigenic $A$. flavus strain was conserved at $37^{\circ} \mathrm{C}$ when compared with $30^{\circ} \mathrm{C}$, at the three ripening stages of cob development examined: milk ripe (R3), dough (R4), and dent (R5). However, pre-harvest biocontrol with a non-toxigenic strain was only effective at the R3 and R4 stages and not at the R5 stage. This was supported by relative expression of the afIR regulatory biosynthetic gene in the different treatments. When exposed to three-way interacting CC factors for control of $\mathrm{AFB}_{1}$ pre-harvest, the non-toxigenic A. flavus strain was effective at R3 and £4 stages but not at the R5 stage. Post-harvest storage of non-GM and GM cultivars showed that control was achievable at $30^{\circ} \mathrm{C}$, with slightly better control in GM-cultivars in terms of the overall inhibition of AFB $_{1}$ production. However, in stored maize, the non-toxigenic strains of $A$. flavus had conserved biocontrol of $\mathrm{AFB}_{1}$ contamination, especially in the GM-maize cultivars under three-way interacting $\mathrm{CC}$ conditions $\left(37^{\circ} \mathrm{C} \times\right.$ $1,000 \mathrm{ppm} \mathrm{CO} \mathrm{CO}_{2}$ and drought stress). This was supported by the relative expression of the afIR gene in these treatments. This study suggests that the choice of the biocontrol strains, for pre- or post-harvest control, needs to take into account their resilience in CC-related abiotic conditions to ensure that control of $\mathrm{AFB}_{1}$ contamination can be conserved.

Keywords: resilience, biocontrol, aflatoxins, climate change, non-toxigenic Aspergillus flavus, non-GM maize, GM maize 


\section{INTRODUCTION}

There has been significant interest in developing biocontrol agents for aflatoxin $\mathrm{B}_{1}\left(\mathrm{AFB}_{1}\right)$ control in staple commodities, especially maize. Indeed, there are some commercial products based on individual non-aflatoxigenic $A$. flavus strains or mixtures of such strains for reducing $\mathrm{AFB}_{1}$ contamination of maize and groundnuts in West and East Africa and in the USA for control of toxin contamination in cotton and groundnuts (Lyn et al., 2009; Abbas et al., 2011; Bandyopadhyay et al., 2016; Mauro et al., 2018; Kagot et al., 2019).

Abiotic factors, especially drought stress, can have a major impact on maize growth especially during the critical silking period, which can allow both pest damage and increase in the colonization by $A$. flavus resulting in $\mathrm{AFB}_{1}$ contamination. In some cases, pest damage has been reduced by the use of GM cultivars, which have resistant genes for pesticides and/or herbicides. This can reduce the entry points for A. flavus and reduce contamination. However, under expected climate change (CC) conditions, which involves interactions between key abiotic factors such as the predicted increase in environmental $\mathrm{CO}_{2}$ (400 vs. $1,000-1,200 \mathrm{ppm})$, elevated temperature $\left(+2-4^{\circ} \mathrm{C}\right)$, and extreme changes in drought/wet regimes, there have been few studies to examine the resilience of non-toxigenic A. flavus biocontrol strains used for toxin reduction in maize and groundnuts. Many maize growing regions are considered hot spots for an impact of these environmental pressures. Indeed, work on A. flavus colonization of maize grain has shown that interacting conditions of $+2-5^{\circ} \mathrm{C}$, elevated $\mathrm{CO}_{2}(650-1,000 \mathrm{ppm})$, and drought stress can result in an increase in both regulatory (aflR) and structural genes (aflD) involved in $\mathrm{AFB}_{1}$ biosynthesis as well as other secondary metabolite genes in maize grain and lead to a significant stimulation in $\mathrm{AFB}_{1}$ contamination (Battilani et al., 2016; Medina et al., 2017a; Gilbert et al., 2018). Bearing this in mind, it is thus surprising that while biocontrol of toxigenic A. flavus using microbial antagonists and non-toxigenic strains of $A$. flavus has been examined for many years, their resilience has never been examined under expected CC regimes (Cotty, 1994; Abbas et al., 2011; Bandyopadhyay et al., 2016; Weaver et al., 2016; Kagot et al., 2019). Some studies have examined the impact of non-toxigenic A. flavus strains and other microbial biocontrol agents on temporal control of $\mathrm{AFB}_{1}$ in maize stored under different temperature and water availabilities (Mohale et al., 2013; Al-Saad et al., 2016; Medina et al., 2017a). However, the relative resilience of the biocontrol strains for control of mycotoxin production under CC scenarios has not previously received any attention (Medina et al., 2017b). It is very important to understand how the potential biocontrol strains targeting $\mathrm{AFB}_{1}$ control in maize may behave under interacting $\mathrm{CC}$ abiotic factors and whether they have the necessary resilience to reduce biosynthesis of $\mathrm{AFB}_{1}$ in situ.

The objectives of this study were to examine (1) the effect of ripening stage of maize cobs on rates of colonization and $\mathrm{AFB}_{1}$ production by $A$. flavus in relation to interactions between two-way abiotic factors of temperature $x$ water availability (water activity, $\mathrm{a}_{\mathrm{w}}$ ); (2) the effect of these two-way interacting factors on the control of $\mathrm{AFB}_{1}$ contamination using 50:50 ratios of non-toxigenic and toxigenic strains in maize cobs of different ripening stages and in stored non-GM and isogenic GM maize cultivars; and (3) the effect of three-way interacting CC abiotic factors on resilience of non-toxigenic A. flavus strains in terms of reducing the expression of key biosynthetic genes involved in aflatoxin synthesis, and on phenotypic $\mathrm{AFB}_{1}$ contamination, in these two types of maize cultivars.

\section{MATERIALS AND METHODS}

\section{Fungal Strains}

Two non-toxigenic strains of A. flavus isolated from Mexican and Brazilian maize were used in these experiments ( $\mathrm{AFL}^{-} \mathrm{Mex} 02$; AFL4 ${ }^{-}$). Both strains were examined molecularly to confirm that key genes in the biosynthetic cluster for aflatoxins were deleted using the multiplex PCR method developed by Callicott and Cotty (2015). Different toxigenic strains including one Mexican strain ( $\mathrm{ALF}^{+}-\mathrm{Mex} 01$, isolated from Mexican maize), a type strain NRRL3375 (AFLe ${ }^{+}$, and one Brazilian toxigenic strain $\left(\mathrm{AFLb}^{+}\right.$, isolated from Brazilian maize), all known $\mathrm{AFB}_{1}$ producers were used. Table 1 summarizes the strains used in this study. The type strain was kindly provided by Prof. D. Bhatnagar, Southern Regional Research Centre, New Orleans, LA, USA.

\section{Pre-harvest Studies With Maize Cobs of Different Ripening Ages for Resilience of Biocontrol of $\mathrm{AFB}_{1}$}

Maize cobs of different ripening stages (R3: Milk; R4: Dough; R5: Dent) were obtained from the NIAB farm (National Institute of Agriculture and Botany; Cambridge, UK). The type of maize was ES Regain (Euralis Semences; forage maize). Harvested maize cobs of different ripening ages were brought to the laboratory where the water activity $\left(a_{w}\right)$ of sub-samples of detached kernels from the entire cob (5-10 maize kernels from the apical, middle, and distal parts of the cobs) was measured (AQUALAB ${ }^{\circledast}$ Series TE4; Decagon Devices Inc., Pullman, WA, USA). Maize cobs were then divided into batches and snap frozen in liquid nitrogen and stored at $-20^{\circ} \mathrm{C}$ for later use in the experiments. The $\mathrm{a}_{\mathrm{w}}$ of the R3 (milk ripe), R4 (dough), and R5 (dent) stages was found to be $0.985,0.976$, and 0.958 , respectively.

TABLE 1 | List of toxigenic and non-toxigenic strains used in this study.

\begin{tabular}{|c|c|c|c|}
\hline Strain code & Source & $\begin{array}{l}\text { Aflatoxin } B_{1} \\
\text { producer }+/-\end{array}$ & Deleted genes \\
\hline AFL-MEX01- & White maize/Mexico & $\begin{array}{l}\text { Naturally very } \\
\text { low producer* }\end{array}$ & None \\
\hline AFL-MEX02 & White maize/Mexico & Producer & \\
\hline $\mathrm{AFL}^{-}$ & $\begin{array}{l}\text { GM maize P30F53 H®, } \\
\text { Brazil }\end{array}$ & Non-producer & $\begin{array}{l}\text { afIN, afIE, afIS. } \\
\text { aflB. afIA }\end{array}$ \\
\hline $\mathrm{AFLB}^{+}$ & $\begin{array}{l}\text { Landrace maize red grain, } \\
\text { Brazil }\end{array}$ & Producer & \\
\hline NRRL3357 & $\begin{array}{l}\text { Peanuts (type strain, ARS, } \\
\text { USDA) }\end{array}$ & Producer & \\
\hline
\end{tabular}

*Less than the limit of quantification. 
The fungal strains were all point inoculated on 3\% Maize Meal Agar (MMA, $0.98 \mathrm{a}_{\mathrm{w}}$ ) and incubated at $25^{\circ} \mathrm{C}$ for 7 days, and the conidial spore suspensions made by using a loop and decanting spores into $9 \mathrm{ml}$ of sterile water $+0.5 \%$ Tween $8-0$ solution in $25 \mathrm{ml}$ Universal bottle. The conidial spore concentrations were measured with a hemocytometer, and then diluted with sterile water as required, to obtain a final concentration of $1 \times 10^{4}$ spores $/ \mathrm{ml}$.

The flash-frozen cobs were thawed at $4^{\circ} \mathrm{C}$ for $24 \mathrm{~h}$. The maize cobs were divided into three segments, and these were point inoculated. Each treatment consisted of 3-4 replicate maize cob segments taken at random from the batch of each ripening age. These were point inoculated by damaging a single kernel with a surface sterilized needle and then decanting a $10 \mu$ droplet containing $10^{4}$ conidia/ml of the A. flavus type strain. These were incubation in separate environmental chambers at 30 and $37^{\circ} \mathrm{C}$. The equilibrium relative humidity (ERH) of the atmosphere was maintained at the actual $\mathrm{a}_{\mathrm{w}}$ levels of the cobs by using glycerol/water solutions of the same $a_{w}$ as the maize cob ripening stages. The colonization rate was measured over a 10-day period, and the $\mathrm{AFB}_{1}$ contamination quantified at the end of the experimental period only.

Subsequent studies examined the biocontrol of the toxigenic A. flavus strain and $\mathrm{AFB}_{1}$ control in each of the ripening stages as described previously by Samsudin et al. (2017). The different ripening stages of the cobs were incubated in separate environmental chambers to stabilize for 3 hours at $25^{\circ} \mathrm{C}$ until inoculation. The control treatment used was inoculated with the toxigenic $A$. flavus $\left(\mathrm{MEX01}^{+}\right)$or the type NRRL3375 strain alone. The biological control agent (BCA) treatments consisted of a 50:50 conidial inoculum ratio of pathogen:antagonist. This was used based on previous studies where different inoculum ratios were used of toxigenic:non-toxigenic strains of $A$. flavus, which showed that $50: 50$ or $25: 75$ ratios, respectively, gave similar levels of $\mathrm{AFB}_{1}$ control as described previously (Medina et al., 2017a). The cob sections were point inoculated with $100 \mu \mathrm{l}$ of the treatments after damage to a single kernel using a surface sterilized needle and incubated at $30^{\circ} \mathrm{C}$ for 10 days (Samsudin et al., 2017). In all cases, 3-4 replicates per treatment were used. Each environmental chamber included $250 \mathrm{ml}$ of a sterile solution of glycerol/water to maintain the ERH at the same level as the cob ripening stage $\mathrm{a}_{\mathrm{w}}$. The colony diameter was measured at the end of the incubation period. For aflD and aflR gene expression, contaminated kernels from the colonized area were carefully removed at random with a pair of forceps and immediately frozen in liquid $\mathrm{N}_{2}$ and kept at $-80^{\circ} \mathrm{C}$ for subsequent RNA extraction and RT-qPCR as detailed previously (Al-Saad et al., 2016). The rest of the colonized cob was kept at $-20^{\circ} \mathrm{C}$ for $\mathrm{AFB}_{1}$ extraction; clean-up was done using an immune-affinity column (IAC) and quantified by HPLC-FLD. The limit of detection was $<1.0 \mathrm{ng} / \mathrm{g}$.

\section{Post-harvest Studies With Non-GM and GM-Maize Cultivars}

Two cultivars of non-GM maize and its isogenic GM lines were selected for the post-harvest biocontrol studies (Table 2). For these studies, batches of the maize grain were gamma-irradiated
TABLE 2 | Maize cultivars (non-GM and GM) selected for biocontrol in situ as substrate for $A$. flavus development.

\begin{tabular}{|c|c|c|c|c|}
\hline $\begin{array}{l}\text { Conventional } \\
\text { cultivar (non- } \\
\text { GM) }\end{array}$ & $\begin{array}{l}\text { Isogenic } \\
\text { line (GM) }\end{array}$ & Event name ${ }^{1}$ & $\begin{array}{l}\text { Inserted } \\
\text { gene }\end{array}$ & Traits tolerance \\
\hline \multirow{5}{*}{ M20-A78 CON } & \multirow{5}{*}{$\begin{array}{l}\text { M20-A78 } \\
\text { PW® }\end{array}$} & \multirow{5}{*}{$\begin{array}{l}\text { MON89034 + } \\
\text { NK603 + } \\
\text { TC1507 }\end{array}$} & CP4 EPSPS & HT-Glyphosate \\
\hline & & & & $\begin{array}{l}\text { HT-Glufosinate } \\
\text { ammonium }\end{array}$ \\
\hline & & & Cry2Ab2 & \\
\hline & & & Cry1F & IR-Lepidopteran \\
\hline & & & Cry1A.105 & \\
\hline \multirow{3}{*}{ P30F53 CON } & \multirow{3}{*}{ P30F53 H® } & \multirow{3}{*}{$\begin{array}{l}\text { DAS1507 + } \\
\text { T25 }\end{array}$} & PAT & $\begin{array}{l}\text { HT-Glufosinate } \\
\text { ammonium }\end{array}$ \\
\hline & & & BLA & $\begin{array}{l}\text { Antibiotic } \\
\text { resistance }\end{array}$ \\
\hline & & & Cry1F & IR-Lepidopteran \\
\hline
\end{tabular}

IR, insect resistance; HT, herbicide tolerance; $P W \circledast$, PowerCore; $H ®$, Pioneer Hi-Breed. ${ }^{1}$ Event name refers to the unique code to access the information about the trait at http://www.isaaa.org/gmapprovaldatabase/eventslist/default.asp

(12-15 kGy) in order to eliminate the natural contaminants but retain germinability of the kernels. The $\mathrm{a}_{\mathrm{w}}$ of the maize treatments was modified to 0.98 and 0.95 with the addition of sterile water based on the moisture absorption curve for each cultivar. These were mixed thoroughly to ensure that the spore inoculum was well distributed throughout the maize grain. The number of spores added to each cultivar was calculated as 10 spores per gram of maize from a solution of $10^{3}$ spores $/ \mathrm{ml}$. After the addition of the water, the maize kernels were kept at $4^{\circ} \mathrm{C}$ for $24 \mathrm{~h}$ for full absorption and equilibration. The water availability was checked by measuring the $\mathrm{a}_{\mathrm{w}}$ using the AquaLab ${ }^{\circledR}$ 4TE (Decagon, USA).

The non-toxigenic and toxigenic strains of A. flavus were incubated on MMA for 7 days at $30^{\circ} \mathrm{C}$ and then used to prepare the conidial spore inoculum. A final concentration of $10^{3}$ spores/ml was obtained. A ratio of 50:50 (toxigenic:nontoxigenic strains) was used. Previous showed that this as an effective inoculum load for biocontrol of $\mathrm{AFB}_{1}$ production (Mohale et al., 2013; Samsudin and Magan, 2016). The spore suspensions were mixed in a 50:50 ratio prior to inoculation of the maize kernels. The controls consisted of 100:0 and 0:100 ratios for the two control treatments.

A $10 \mathrm{~g}$ sample of maize grain were placed aseptically into glass culture vessels (Magenta ${ }^{\mathrm{Tm}}$, Sigma, USA) with vented lids (10 $\mathrm{mm}$ with a polypropylene membrane $0.22 \mu \mathrm{m}$ pore size) to allow gase exchange but keeping the environment inside the vessel sterile. These were inoculated with a $100 \mu$ l conidial mixture and shaken to distribute the conidia. The jars were placed in closed plastic environmental chambers that also contained a glycerol/water solution of the same $\mathrm{a}_{\mathrm{w}}$ as the maize kernels to keep the ERH the same as the target treatments. The glycerol/water solution was renewed every 3 days. The environmental chambers were incubated at $30^{\circ} \mathrm{C}$ for 20 days. Samples were destructively sampled after 10 and 20 days storage for quantification of $\mathrm{AFB}_{1}$.

The samples for $\mathrm{AFB}_{1}$ quantification were oven dried at $65^{\circ} \mathrm{C}$ for $48 \mathrm{~h}$ to remove the water and stop fungal growth. These were then ground using a laboratory blender with a 
stainless steel blade (Waring, Stamford, USA). The effects on aflD and aflR gene expression were only examined after 10 days in all the treatments and replicates. The samples for gene expression were snap frozen in liquid nitrogen and stored at $-80^{\circ} \mathrm{C}$ for subsequent RNA extraction. All studies were carried out with two non-GM and their isogenic GM cultivars. All experiments were carried out with at least three replicates per treatments and repeated once.

\section{Studies of Resilience of Non-toxigenic Strains of $A$. flavus When Controlling Aflatoxin $B_{1}$ Contamination of Maize Cultivars Under Climate Change Conditions \\ Fungal Strains}

Studies were carried out with two non-aflatoxigenic strains of A. flavus $\left(\mathrm{AFL}^{-}: \mathrm{Mex} 02 ; \mathrm{AFL} 4^{-}\right)$isolated from Mexican and Brazilian maize, respectively, based on their ability to reduce $\mathrm{AFB}_{1}$ in previous in vitro and in situ studies (Rodríguez-Sixtos, 2017; Marcon Gasperini, 2019). The native toxigenic strains $\left(\mathrm{AFL}^{+} \mathrm{MEX} 01 ; \mathrm{AFLb}^{+}\right.$; and the AFLe type strain) with known $\mathrm{AFB}_{1}$ production capacity were used as the toxigenic pathogen in these studies.

Pre-harvest studies involved the use of maize cobs at the R4 (dough) and R5 (dent) stages only. Post-harvest studies used the two non-GM and isogenic GM maize cultivars. The same modification procedures were used as detailed previously. A ratio of 50:50 conidia (toxigenic A. flavus: non-toxigenic A. flavus) were used. The controls consisted again of only the toxigenic or non-toxigenic conidial concentrations as detailed previously.

The post-harvest maize grain treatments were modified to 0.98 and $0.95 \mathrm{a}_{\mathrm{w}}$ with the addition of sterile water using the moisture adsorption curve of each cultivar to obtain the target treatment regimes. The maize treatments and replicates were inoculated with a conidial mixture of non-toxigenic and toxigenic strains as described previously $\left(10^{3}\right.$ conidia $/ \mathrm{ml}$ and addition of the mixture resulting in approx. 10 conidia/g maize). The only exception was that for the cultivars AS $1555 \mathrm{CON}$ and $\mathrm{PRO}^{\circledR}$, and $\mathrm{P} 2530 \mathrm{CON}$ and $\mathrm{Hx}^{\circledR}$ were only conducted at 0.98 $\mathrm{a}_{\mathrm{w}}$ because of a limited amount of maize grain of these cultivars available for the experiment.

For the CC study, the separate treatments were placed in plastic environmental chambers (Lock \& Lock HPL890 16 L) containing a glycerol/water solution of the same $a_{w}$ as the treatments as described previously. The environmental conditions were set to flush the $\mathrm{CO}_{2}$ treatments of $400 \mathrm{ppm}$ (atmospheric $\left.\mathrm{CO}_{2}\right)$ and $1,000 \mathrm{ppm}$. The elevated $\mathrm{CO}_{2}$ content was achieved by using a gas cylinder containing a certified concentration of $1,000 \mathrm{ppm} \mathrm{CO}_{2} /$ synthetic air at 200 bar prepared by the British Oxygen Company (Guildford, UK). The chambers were vented, and for the $1,000 \mathrm{ppm}$ treatment flushed with $\mathrm{CO}_{2}$, every $12 \mathrm{~h}$ for the 20 -day experimental period. The concentration of $\mathrm{CO}_{2}$ was regulated to $3 \mathrm{~L} / \mathrm{min}$ (LPM) with a gas flow meter (Alicat Scientific, Arizona, USA) and flushed for 10-12 min, which corresponded to $2 \times$ the volume of each chamber. After flushing, the inlet and outlet valves of the chambers were immediately closed, and they were incubated at 30 or $35^{\circ} \mathrm{C}$. The control chambers were flushed with air (400 ppm) and similarly incubated. At the end of the experiment, samples were destructively sampled for gene expression studies (10 days) and for $\mathrm{AFB}_{1}$ quantification (10,20 days). The samples for toxin quantification were oven dried at $65^{\circ} \mathrm{C}$ for $48 \mathrm{~h}$ to remove the water and stop any fungal growth. The samples were ground using the laboratory blender as described previously.

\section{Gene Expression Studies}

The gene expression studies were performed using the samples from the different maize ripening stages (pre-harvest studies) and those from the stored maize grain experiments after 10 days incubation. This time frame was chosen based on previous studies with both $A$. flavus and $A$. parasiticus that suggested gene expression of several of the toxin biosynthetic genes had optimal peaks of expression after 8-10 days growth (SchmidtHeydt et al., 2008). The gene expression of the chosen genes was only performed for the interaction between toxigenic/ non-toxigenic strains $\mathrm{MEX01}^{+}: \mathrm{MEX02}^{-}$and $\mathrm{AFLb}^{+}: \mathrm{AFL4}^{-}$, respectively. The type strain $\mathrm{AFLe}^{+}$(NRRL3357) treatments were not included because the $\mathrm{AFB}_{1}$ production was lower than the native Mexican or Brazilian toxigenic strains.

The treatments/replicates were stored at $-80^{\circ} \mathrm{C}$ and transferred to reinforced $7 \mathrm{ml}$ tubes designed for use in the Precellys $24^{\circledR}$ (Bertin, FR) homogenizer with three glass beads $(6.5 \mathrm{~mm})$. The tubes were kept in liquid $\mathrm{N}_{2}$ until use. The kernels were homogenized into a fine powder using a 6,500 rpm cycle for $30 \mathrm{~s}(2 \times 15 \mathrm{~s})$ and then immersing them in liquid $\mathrm{N}_{2}$ for $5 \mathrm{~min}$ and the cycle repeated. Approximately $50 \mathrm{mg}$ of the powder was transferred to a $2 \mathrm{ml}$ Eppendorf RNase/DNAse free to proceed with the extraction of the total RNA.

\section{RNA Extraction}

Total RNA isolation was carried out using the Spectrum $^{\mathrm{Tm}}$ Plant Total RNA Kit (Sigma-Aldrich Co, USA) according to the manufacturer instructions. The observations for samples with high amounts of starch were taken into account. For this reason, samples were incubated at room temperature, and $1 \mathrm{ml}$ of lysis buffer added to the $50 \mathrm{mg}$ of powder. RNA samples were treated with RNase-Free DNAse set (Qiagen, Hilden, Germany). The purity and concentrations of RNA were examined by measuring the absorbance of $2 \mu \mathrm{l}$ of sample Genova-Nano spectrophotometer (JenWay, Staffordshire, UK). Samples were considered to be of good purity when the ratio $\mathrm{A}_{260} / \mathrm{A}_{280}$ was 22.0. The RNA integrity was verified using Experion ${ }^{\mathrm{Tw}}$ RNA StdSens in an Experion ${ }^{\text {Tn }}$ automated electrophoresis system (Bio-Rad, California, USA) or by gel electrophoresis, and an RQI $>6$ was used as a threshold for integrity. The samples were kept at $-80^{\circ} \mathrm{C}$ until use.

\section{Relative Gene Expression Using Quantitative Polymerase Chain Reactions}

Real-time quantitative PCR (RT-qPCR) assays were used to amplify the structural alfD and the regulatory gene aflR of 
the aflatoxin biosynthetic pathway as target genes (Table 3). The $\beta$-tubulin gene was used as the control gene. The aflD qPCR was previously optimized by Abdel-Hadi et al. (2010), whereas aflR was optimized by Medina et al. (2015) following the same method as that for the aflD gene.

Two RT-qPCR assays were carried out, one optimized to amplify the target $a f l \mathrm{D}$ and the housekeeping $\beta$-tubulin genes, and the other one to quantify the aflR gene expression and for the $\beta$-tubulin gene. The qPCR reactions were prepared in triplicate for each biological replicate $(n=9)$. The TaqMan system with different primers and probes was used in all cases. Both reaction mixtures consisted of $6.25 \mu \mathrm{lm}$ Premix Ex Taq ${ }^{\mathrm{Tm}}$ (Takara Bio Inc., Otsu, Japan), $830 \mathrm{nM}$ of each primer, $330 \mathrm{nM}$ of each probe, and $1.5 \mu \mathrm{l}$ of cDNA template in a final volume of $12.5 \mu \mathrm{l}$. The optimal thermal cycling conditions included an initial step of $10 \mathrm{~min}$ at $95^{\circ} \mathrm{C}$ and all 50 cycles at $95^{\circ} \mathrm{C}$ for $15 \mathrm{~s}, 55^{\circ} \mathrm{C}$ for $20 \mathrm{~s}$, and $72^{\circ} \mathrm{C}$ for $30 \mathrm{~s}$. The assays were carried out using a CFX96 Touch $^{\text {Tn }}$ Real-Time PCR detection system (Bio-Rad, CA, USA).

\section{Relative Quantification of the Expression}

Relative quantification of $a f l \mathrm{D}$ and aflR genes was performed using the housekeeping gene $\beta$-tubulin (ben) as an endogenous control to normalize the quantification of the target in the relative quantification assays and used for all treatments. Quantification cycle $(\mathrm{Cq})$ determinations were automatically performed by the instrument using the default parameters, and the expression ratio was calculated using the $2^{-\Delta \Delta C t}$ method as proposed by Livak and Schmittgen (2001). The control of each condition corresponded to $\mathrm{AFLb}^{+}$without the presence of the BCA.

\section{Mycotoxin Quantification}

For the extraction of $\mathrm{AFB}_{1}$, a $2 \mathrm{~g}$ sample was ground and transferred to a glass vial and mixed with $8 \mathrm{ml}$ of extraction solution (methanol:water; 80:20 v/v). The samples were agitated with a magnetic stirrer for $1 \mathrm{~h}$ at room temperature and then centrifuged to allow phase separation. The liquid phase was transferred to a new $15 \mathrm{ml}$ polypropylene tube and $100 \mu \mathrm{l}$ of the extract mixed with $900 \mu \mathrm{l}$ of mobile phase (methanol: acetonitrile:water 30:15:60 v/v/v) in a $2 \mathrm{ml}$ Eppendorf tube and vortexed and filtered using a nylon filter $(13 \mathrm{~mm} \times 0.22 \mu \mathrm{m})$ directly into an amber silanized vial. The samples were injected into the HPLC system, and samples below the limit of detection $(<1.0 \mathrm{ng} / \mathrm{g})$ were cleaned-up and concentrated using an IAC as described previously and then reinjected.

\section{IAC Analysis}

The extract of the samples was diluted 2:20 in 1× PBS (phosphate buffered saline, Fisher Scientific, USA). The $\mathrm{pH}$ of the extract was checked to ensure that this was not lower than 7.0 to ensure good performance of the IACs (AflaStar ${ }^{\mathrm{m}} \mathrm{R}$, RomerLabs, Austria). The IACs were brought to room temperature prior to use and were attached to a SPE vacuum manifold (Phenomenex, CA, USA). Above each IAC, a $25 \mathrm{ml}$ reservoir was used to hold the sample extract. Following the manufacturers' instructions, the buffer in the IAC was removed, and the sample extract passed through the column at a speed of 1 to $3 \mathrm{ml} / \mathrm{min}$. This was followed by $20 \mathrm{ml}$ of $1 \times$ PBS for the clean-up (10 ml was added in the reservoir and $10 \mathrm{ml}$ added directly into the IAC). The last step was the elution with $1.5 \mathrm{ml}$ of methanol. For best recovery, the elution was performed by adding $3 \times 500 \mu \mathrm{l}$ of methanol. The eluted samples were evaporated to dryness using a vacuum evaporator (miVac Quattro Concentrator - Genevac, Leicestershire, UK) at $45^{\circ} \mathrm{C}$ for $3 \mathrm{~h}$. The dried extract was re-suspended in $500 \mu \mathrm{l}$ mobile phase, transferred to an amber silanized vial, and injected into the HPLC for $\mathrm{AFB}_{1}$ quantification.

\section{HPLC Analysis}

The quantification of $\mathrm{AFB}_{1}$ in the maize grain was done by reverse-phase HPLC. The HPLC system used was an Agilent 1,200 series (Agilent, Santa Clara, USA) with a fluorescence detector $\left(\lambda_{\text {exc }} 360 \mathrm{~nm} ; \lambda_{\mathrm{em}} 440 \mathrm{~nm}\right)$ and post-column derivatization with a UVE photochemical reactor with UV-Light (LCTech $\mathrm{GmbH}$, Germany). A $\mathrm{C}_{18}$ column (Agilent Zorbax ${ }^{\circledR}$ Eclipse Plus, $2.1 \times 100 \mathrm{~mm}, 3.5 \mu \mathrm{m}$ particle size) preceded by a Phenomenex $^{\circledR}$ Gemini C18 guard column cartridge $3 \mathrm{~mm} \times$ $3 \mu \mathrm{m}$ (Phenomenex, CA, USA) was used for separation. Followed by isocratic elution with methanol:water:acetonitrile (30:60:15, $\mathrm{v} / \mathrm{v} / \mathrm{v}$ ) and a mobile phase flow rate of $1.0 \mathrm{ml} / \mathrm{min}$. The injection volume was 5-50 $\mu \mathrm{l}$ according to each set of samples. A set

TABLE 3 | Nucleotide sequences of primers for RT-qPCR assays designed on the basis of the afID, aflR, and $\beta$-tubulin genes.

\begin{tabular}{|c|c|c|c|}
\hline Primer pairs & Gene & Nucleotide sequences $\left(5^{\prime}-3^{\prime \prime}\right)$ & Position \\
\hline norTaq - 1 & & GTCCAAGCAACAGGCCAAGT & $516^{a}$ \\
\hline norTaq - 2 & afID & TCGTGCATGTTGGTGATGGT & $562^{\mathrm{a}}$ \\
\hline nor-Probe & & [FAM]TGTCTTGATCGCGCCCG[BHQ2] & $537^{a}$ \\
\hline aflRTaq - 1 & & TCGTCCTTATCGTTCTCAAGG & $1,646^{b}$ \\
\hline aflRTaq - 2 & aflR & ACTGTTGCTACAGCTGCCACT & $1,735^{b}$ \\
\hline aflR-Probe & & [FAM]AGCAGGCACCCAGTGTACCTCAAC[BHQ2] & $1,689^{b}$ \\
\hline benTaq - 1 & & CTTGTTGACCAGGTTGTCGAT & $65^{c}$ \\
\hline benTaq - 2 & $\beta$-tubulin & GTCGCAGCCCTCAGCCT & $99^{c}$ \\
\hline ben-Probe & & [CY5]CGATGTTGTCCGTCGCGAGGCT[BHQ2] & $82^{c}$ \\
\hline
\end{tabular}

${ }^{a}$ Positions are in accordance with the published sequence of the aflD gene of Aspergillus flavus (GenBank accession no. XM_002379908.1); ${ }^{b}$ Positions are in accordance with the published sequences of afIR gene of Aspergillus flavus (GenBank accession no. AF441435.2); ${ }^{\circ}$ Positions are in accordance with the published sequences of $\beta$-tubulin (benA56) gene of Aspergillus flavus (GenBank accession no. AF036803.1). 
of standards was injected (0.05-4 ng of a mixture of aflatoxins per injection), and standard curves were generated by plotting the peak areas against the amounts of each aflatoxin. The recovery of the extraction method for $\mathrm{AFB}_{1}$ in maize was $80 \%$.

\section{Statistical Analyses}

The data from pre-harvest cobs of different ripening stages and the in situ post-harvest experiments (gene expression data, $\mathrm{AFB}_{1}$ ) were analyzed using the Shapiro-Wilk tests to determine normality and Levene's test to assess variance homogeneity. However, the data violated the two assumptions for ANOVA even after transformations and therefore non-parametric tests (KruskalWallis/Wilcoxon; $p=0.05$ ) were used for analyses (Chan and Walmsley, 1997). Where there was significance after the KruskalWallis test, median comparisons for each pair were made using the Wilcoxon-Each Pair test $(p=0.05)$. The correlation of relative gene expression $\times \mathrm{AFB}_{1}$ production was checked using non-parametric Spearman's $(\rho)$ rank correlation coefficient for each $\mathrm{a}_{\mathrm{w}}$ level. The statistical package $\mathrm{JMP}^{\circledR} 14$ (SAS Institute Inc., 2018, Cary, NC, USA) was used to perform the analyses.

The data sets for the effect of CC scenarios on $\mathrm{AFB}_{1}$ production satisfied the requirements for ANOVA after transformation to the cube root. Tests were thus performed comparing the interactions of temperature $\times \mathrm{CO}_{2} \times \mathrm{a}_{\mathrm{w}}$ for each cultivar of maize. The relative gene expression for this study violated the two assumptions for ANOVA, and the differences were compared using non-parametric tests (KruskalWallis/Wilcoxon; $p=0.05$ ). The calibrant (control sample) for the biocontrol experiment was the toxigenic pathogen strain $\left(\mathrm{AFLb}^{+}\right)$in the same conditions as the non-toxigenic strain was applied. For the effects of CC, the control sample refers to normal environmental conditions $\left(30^{\circ} \mathrm{C}, 400 \mathrm{ppm} \mathrm{CO}_{2}\right)$ for each cultivar. The statistical package $\mathrm{JMP}^{\circledR} 14$ (SAS Institute Inc., 2018, Cary, NC, USA) was used to perform the analyses.

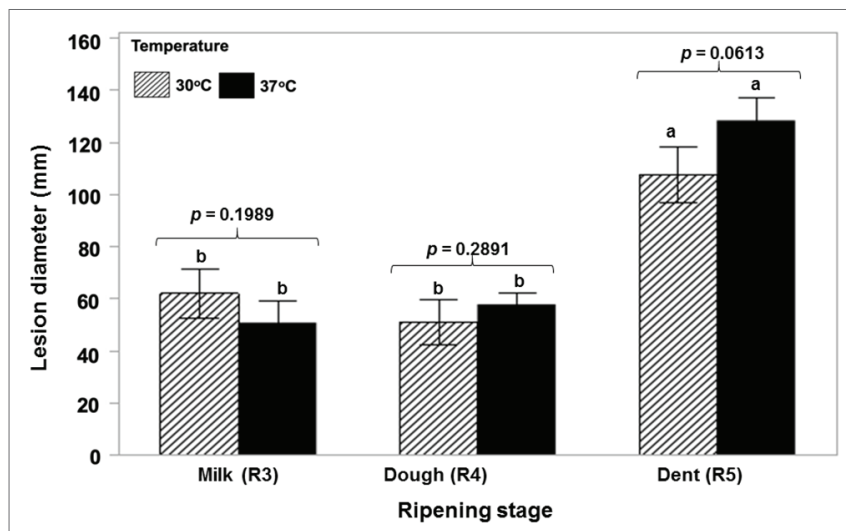

FIGURE 1 | Relative colonization rates of maize cobs of different ripening ages (R3, R4, R5) by a toxigenic strains of $A$. flavus (NRRL 3375) when point inoculated and incubated at the water activity levels of the different growth stages at 30 and $37^{\circ} \mathrm{C}$. Statistical test performed after lesion diameter ( $\left.\mathrm{mm}\right)$ data was transformed to $\log (x+1)$ to achieve normality fit (Shapiro Wilk $p \geq 0.05)$. The values of $p$ indicate no difference between temperatures. Treatments with the same letters indicate no differences in the ripening stages based on the Tukey's HSD test $(p \geq 0.05)$.

\section{RESULTS}

\section{Effect of Maize Cob Ripening Stage and Temperature on Colonization and Aflatoxin $B_{1}$ Contamination}

Figure 1 shows that a toxigenic strain of A. flavus is able to colonize ripening maize cobs of different ages at both

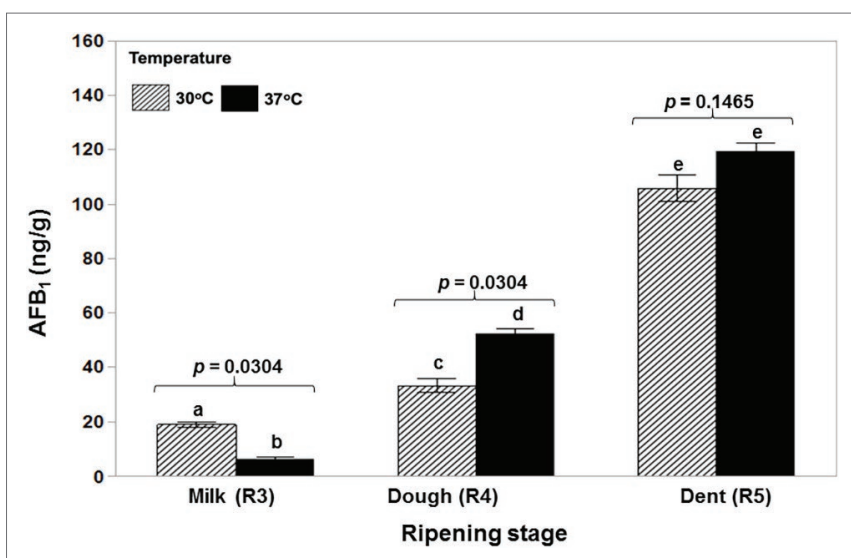

FIGURE 2 | Relative contamination of maize cobs of different ripening ages $(R 3, R 4, R 5)$ with aflatoxin $B_{1}$ when incubated at the actual water activity levels of the maize kernels at the different growth stages at 30 and $37^{\circ} \mathrm{C}$. The toxigenic strain NRRL 3375 was used. The values of $p$ indicate no evidence of difference between temperatures. Ripening stage treatments with the same letters were not significantly different using the Wilcoxon for each pair test $(p \geq 0.05)$. Overall analyses was done using the Non-Parametric data Wilcoxon Test. Ripening stages: R3 $\times$ R $4 \times$ R5, $p=0.0009$; Temperatures: 30 $\times 37^{\circ} \mathrm{C}, p=0.7728$.

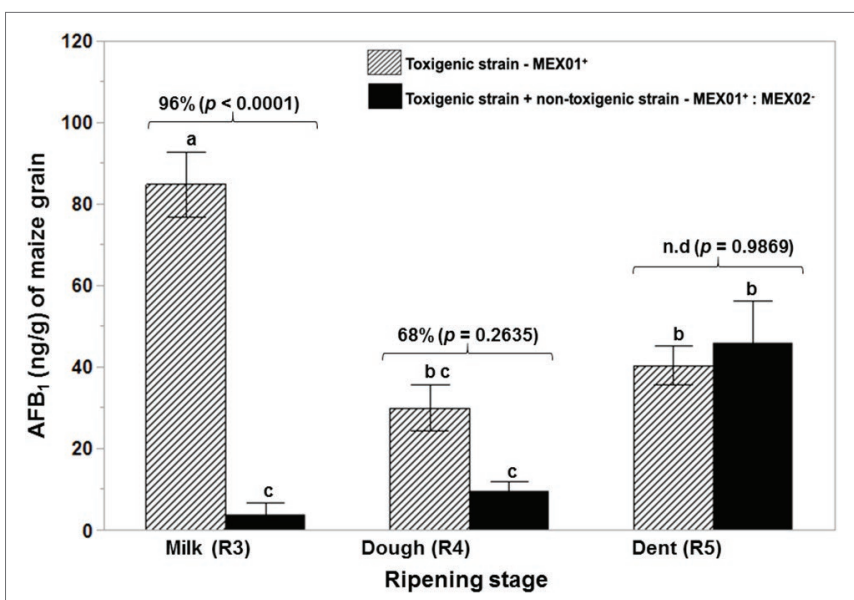

FIGURE 3 | Effect of a non-toxigenic strain (AFL-MEX02) of $A$. flavus when co-inoculated with a wild type toxigenic strain (AFL + MEX01) on aflatoxin $B_{1}$ production when applied as a mixed inoculum (50:50) to maize cobs of different ripening ages $(R 3, R 4, R 5)$ after 10 days at $30^{\circ} \mathrm{C}$. The percentage values above the bars show relative reduction of $\mathrm{AFB}_{1}$, and the values of $p$ $(<0.05)$ indicate evidence of difference from the control (toxigenic strain). Treatments with the same letters show no differences in the ripening stages using the Tukey's HSD test at $5 \%$ significance. n.d. - AFB ${ }_{1}$ reduction not detected. 
30 and $37^{\circ} \mathrm{C}$ in a relatively similar manner with no significant difference between cob ripening stage and temperature. $\mathrm{AFB}_{1}$ production was significantly lower initially at the R3 (milk) stage and $37^{\circ} \mathrm{C}$ and then significantly higher at the R4 (dough) stage and the same temperature. There was no difference at the R5 (dent) stage (Figure 2). Statistically, there was a significant overall effect of ripening stage but not of temperature.

\section{Relative Control of $\mathrm{AFB}_{1}$ Contamination in Ripening Ages of Maize Cobs Using a Non-toxigenic $A$. flavus Strain}

Figure 3 shows the effect of the non-toxigenic strain (AFL-:MEX02) on control of $\mathrm{AFB}_{1}$ production by the toxigenic strain $\left(\mathrm{AFL}^{+} \mathrm{MEX} 01\right)$ on maize cobs of different ripening stages. This shows that the level of control of $\mathrm{AFB}_{1}$ was maximum at the R3 (milk) and R4 (dough) stages $(p=0.05)$. At the R5 (dent) stage, there was no control of toxin production. Plate 1 shows an example of the colonization of maize cobs segments at the R5 stage. This was confirmed by measurement of the relative expression of the regulatory aflR gene, which was downregulated at the R3 and R4 stages in the maize cobs, while in the R5 stage, there was no difference from the toxigenic control gene expression levels (Figure 4).

\section{Post-harvest Control of Aflatoxin Under Different Water Availability Conditions in Non-GM and GM Maize Grain}

Figure 5 summarizes the effect of a non-toxigenic strain (AFL4 ${ }^{-}$) on $\mathrm{AFB}_{1}$ control in maize grain contaminated with two different toxigenic A. flavus $\left(\mathrm{AFLb}^{+} ; \mathrm{AFLe}^{+}\right)$strains on $\mathrm{AFB}_{1}$ control in GM and non-GM cultivars (mean of two cvs of each). This showed that the toxigenic $\mathrm{AFLb}^{+}$strain produced significantly more $\mathrm{AFB}_{1}$ than the $\mathrm{AFLe}^{+}$(NRRL3375) strain. Overall, there was better control of $\mathrm{AFB}_{1}$ in the GM-maize cultivars than the non-GM ones. Although in both GM and non-GM cultivars,
$>90 \%$ control of $\mathrm{AFB}_{1}$ contamination of the maize grain was achieved using the initial inoculum ratio of 50:50 of non-toxigenic:toxigenic conidial inoculum. These studies were carried out at $30^{\circ} \mathrm{C}$ and showed that efficacy was consistent across non-GM and GM cultivars. Figure 6 compares the relative expression of both the aflD and aflR genes in one of the non-GM and GM cultivars at 0.98 and $0.95 \mathrm{a}_{\mathrm{w}}$. The efficacy of the non-toxigenic strain on the toxigenic strains was supported by the effects on the structural and regulatory genes examined. These were significantly downregulated in both non-GM and GM cultivars, although this was more pronounced in the latter one.

\section{Resilience of Non-toxigenic Strains of A. flavus for Control of Aflatoxin $B_{1}$ Under Three-Way Interacting Climate Change Abiotic Conditions in Non-GM and GM Strains}

Two sets of studies were carried out. Pre-harvest studies with a 50:50 mixed conidial inoculum of the non-toxigenic:toxigenic strains were used in maize cobs at the R4 and R5 stages and incubated at 30 or $35^{\circ} \mathrm{C}$ and exposed to elevated $\mathrm{CO}_{2}$ for 10 days. This showed that there were no statistically significant differences in $\mathrm{AFB}_{1}$ contamination between the control and the elevated $\mathrm{CO}_{2}$ treatments $(p=0.05$; means of R4: 545 vs. 390 ; $\mathrm{R} 5=1,125$ vs. $780 \mathrm{ng} / \mathrm{g} \mathrm{AFB}_{1}$ in maize, respectively). The relative expression of the aflD and aflR genes showed that there was an inhibition of the former structural gene expression but not of the latter regulatory gene (data not shown).

Exposure to interacting climate change abiotic factors in post-harvest storage studies was carried out with the two non-GM and isogenic GM cultivars. Figure 7 compares the relative effect of the biocontrol strain $\mathrm{AFL}^{-}$when co-inoculated with the toxigenic strain $\mathrm{AFLb}^{+}$in one of the non-GM and GM cultivars when carried out under existing $\mathrm{CO}_{2}$ conditions (400 ppm) at two $\mathrm{a}_{\mathrm{w}}$ stress levels and comparisons with exposure

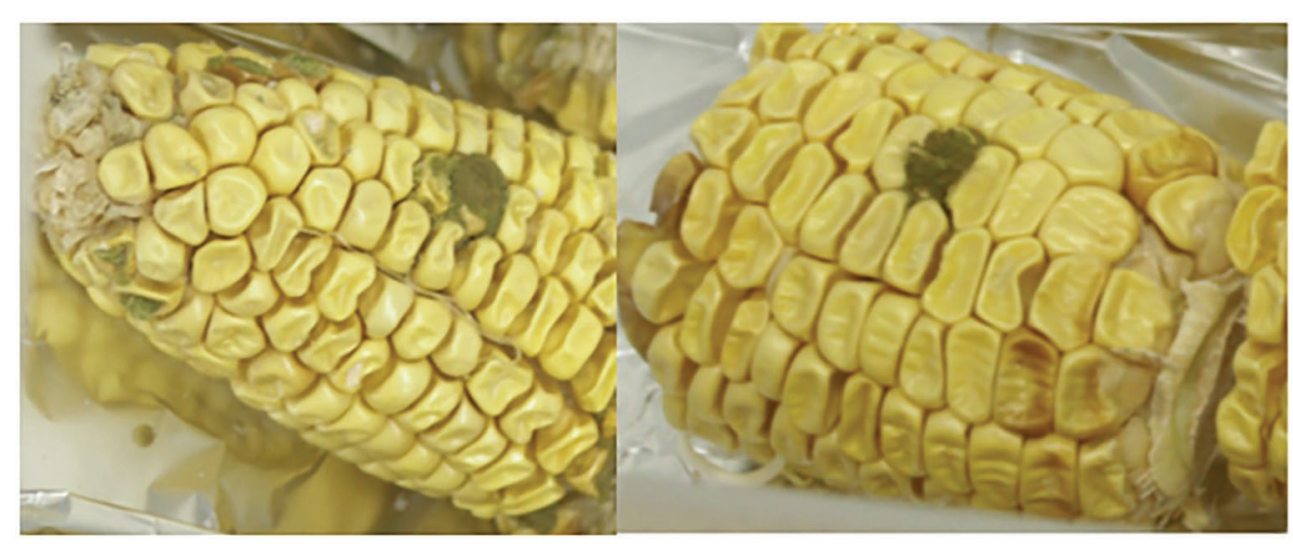

PLATE 1 | Example of colonization of maize cob sections by mixtures of 50:50 inoculum of the toxigenic and non-toxigenic strains (AFL + MEX01:AFL-MEX02), respectively, at the $\mathrm{R} 4$ stage. 


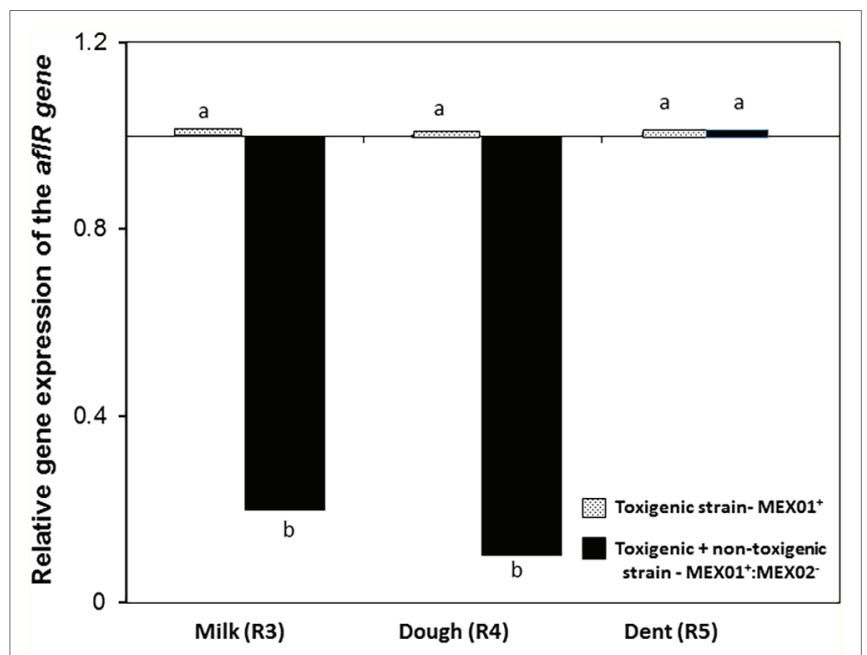

FIGURE 4 | Relative gene expression of the regulatory aflR gene in maize cobs of different ripening stages when co-inoculated with the non-toxigenic and toxigenic strains of $A$. flavus (AFL-MEX02+ AFL + MEX01) after 10 days incubation at $30^{\circ} \mathrm{C}$. Treatments with different letters are significantly different $(p=0.05)$.

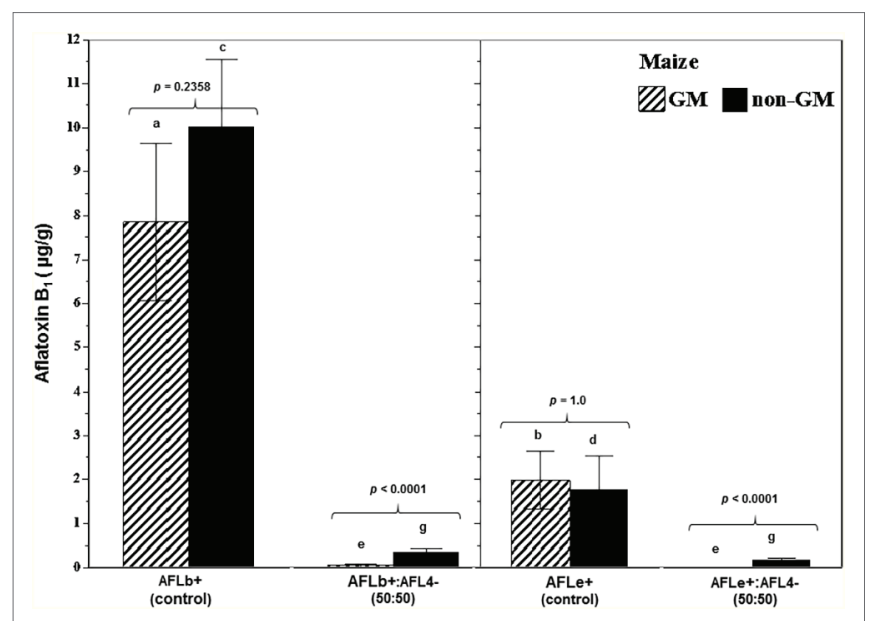

FIGURE 5 | Overall aflatoxin $B_{1}$ contamination of post-harvest stored maize grain treated with a mixture of a non-toxigenic and a toxigenic strain of $A$. flavus in non-GM and GM maize cultivars taking into account the parameters of water availability $(0.98,0.95)$, time of incubation (10, 20 days), and type of maize cultivar (non-GM vs. GM). The grain was inoculated with two different Brazilian or NRRL type toxigenic strains $\left(\mathrm{AFL}^{+}\right.$or $\mathrm{AFLe}^{+}$) and the non-toxigenic Brazilian strain AFL4- in a 50:50 inoculum ratio. Different letters indicate a significant difference $(p<0.05)$ between the strains of the same maize type. The values of $p$ show differences in overall $\mathrm{AFB}_{1}$ content comparing $\mathrm{GM}$ and non-GM maize at 5\% significance. Bars represent mean \pm SE.

to $1,000 \mathrm{ppm} \mathrm{CO}_{2}$. There was higher $\mathrm{AFB}_{1}$ production at 0.98 $\mathrm{a}_{\mathrm{w}}$ than at $0.95 \mathrm{a}_{\mathrm{w}}$. In addition, in the non-GM cultivar, more $\mathrm{AFB}_{1}$ was produced by the toxigenic strain. Overall $\mathrm{AFB}_{1}$ control was more effective at $0.98 \mathrm{a}_{\mathrm{w}}$ than at $0.95 \mathrm{a}_{\mathrm{w}}$ in both existing and future $\mathrm{CO}_{2}$ scenarios. For both $\mathrm{GM}$ and non-GM maize cultivars, the control of $\mathrm{AFB}_{1}$ was similar, suggesting relative resilience of this non-toxigenic strain.
Figure 8 compares the relative expression of the regulatory aflR gene at $35^{\circ} \mathrm{C}$ and $0.98 \mathrm{a}_{\mathrm{w}}$ in the different $\mathrm{CO}_{2}$ treatments (400 and $1,000 \mathrm{ppm} \mathrm{CO}_{2}$ ) with the control at $30^{\circ} \mathrm{C} / 400 \mathrm{ppm}$ $\mathrm{CO}_{2}$ in both non-GM and GM cultivars. This shows that the aflR gene expression was significantly affected at $35^{\circ} \mathrm{C}$ when comparisons were made between existing (400 ppm) and future $(1,000 \mathrm{ppm}) \mathrm{CO}_{2}$ treatments. The relative expression values were relative to those at $400 \mathrm{ppm} \mathrm{CO}_{2}$ and $30^{\circ} \mathrm{C}$ (existing conditions).

\section{DISCUSSION}

This study has examined the pre-harvest and post-harvest resilience of non-toxigenic strains of $A$. flavus for control of $\mathrm{AFB}_{1}$ contamination of maize cultivars, including non-GM and isogenic non-GM with herbicide/pesticide resistant traits for the first time. The ability of the toxigenic strains of $A$. flavus to colonize ripening maize cobs at both 30 and $37^{\circ} \mathrm{C}$ suggests that it is important to screen non-toxigenic biocontrol strains for resilience to fluxes in temperature and the ability to tolerate a range of water availability conditions to ensure that competitiveness both pre- and post-harvest can be maintained. The fact that $\mathrm{AFB}_{1}$ control was more effective at the milky ripe (R3) and dough stages (R4) of maize cobs pre-harvest suggests that the window for control based on the $a_{w}$ range at these stages may be an important consideration for application of the biocontrol strain. Recently, Giorni et al. (2019) showed that relative infection of ripening maize cobs by $A$. flavus, Fusarium verticillioides and $F$. graminearum influenced the colonization and the mixture of mycotoxins contaminating the maize at harvest. Thus, the presence of A. flavus impacted on the contamination of the maize grain with other mycotoxins such as fumonisin $\mathrm{B}_{1}\left(\mathrm{FB}_{1}\right)$ and deoxynivalenol, perhaps because of the its wider range of temperature and water availability during silking.

The biocontrol of $\mathrm{AFB}_{1}$ contamination at different ripening stages is important. They represent different $\mathrm{a}_{\mathrm{w}}$ levels as well as different nutritional compositions during the silking process. However, since ripening stage did not affect the ability of the toxigenic strain to colonize the cobs, this suggests that toxigenic A. flavus strains are able to colonize maize cobs rapidly during silking, if entry points are available for infection. Thus, the resilience of the non-toxigenic biocontrol strains is critical to facilitate niche exclusion or effectively outcompete the toxigenic strains either in soil or in the later silking process (Medina et al., 2017b). Previously, it has been suggested that A. flavus is adapted to the ripening stages of maize, expressing specific genes to utilize the available carbon sources (CS; Reese et al., 2011; Dolezal et al., 2014). The non-toxigenic strain was effective in controlling $\mathrm{AFB}_{1}$ production at the milky ripe and dough stages. However, at the dent stage, it was less effective. This was supported by the effects on the gene expression of one of the key regulatory genes (aflR) involved in secondary metabolite production. Previously, Verheecke et al. (2015) studied the efficacy of Streptomyces strains against toxigenic A. flavus strains on synthetic media. They examined five different 


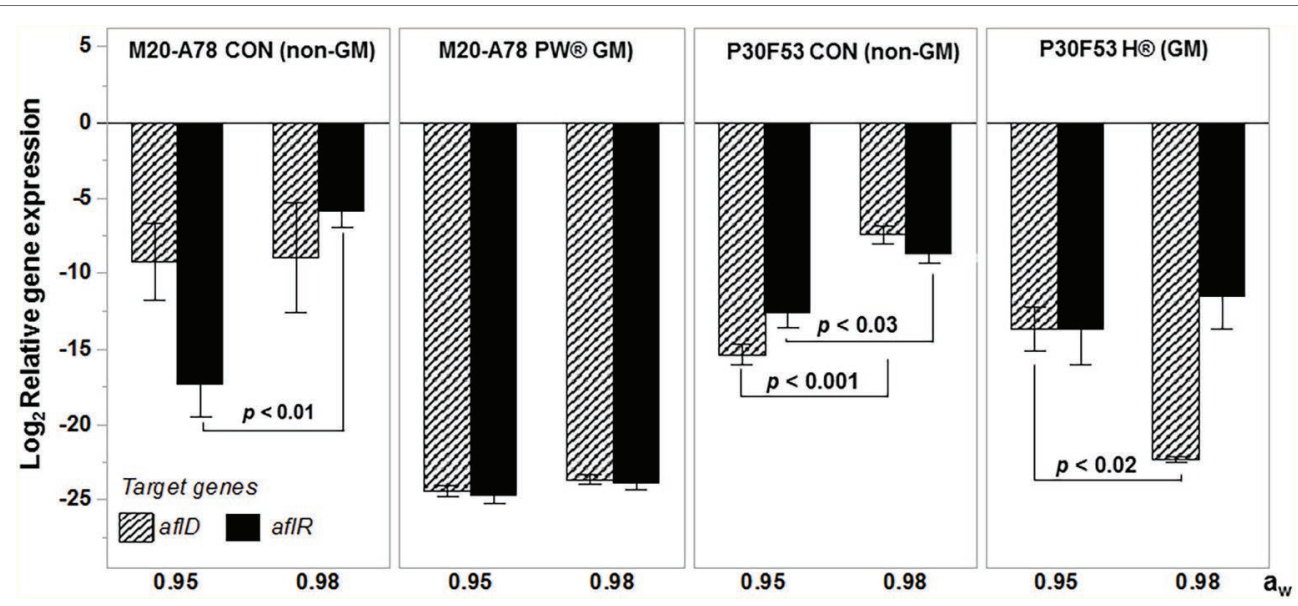

FIGURE 6 | Effect of biocontrol using the Brazilian AFL4-:AFLb+ mixed non-toxigenic and toxigenic strain 50:50 ratio inoculum on the relative gene expression of the structural afID and regulatory afIR genes on one of the non-GM and isogenic-GM cultivars stored post-harvest at both 0.98 and 0.95 water activity. The values of $p$ show differences in overall $\mathrm{AFB}_{1}$ content comparing $\mathrm{GM}$ and non-GM maize at $5 \%$ significance. Bars represent mean $\pm \mathrm{SE}$.

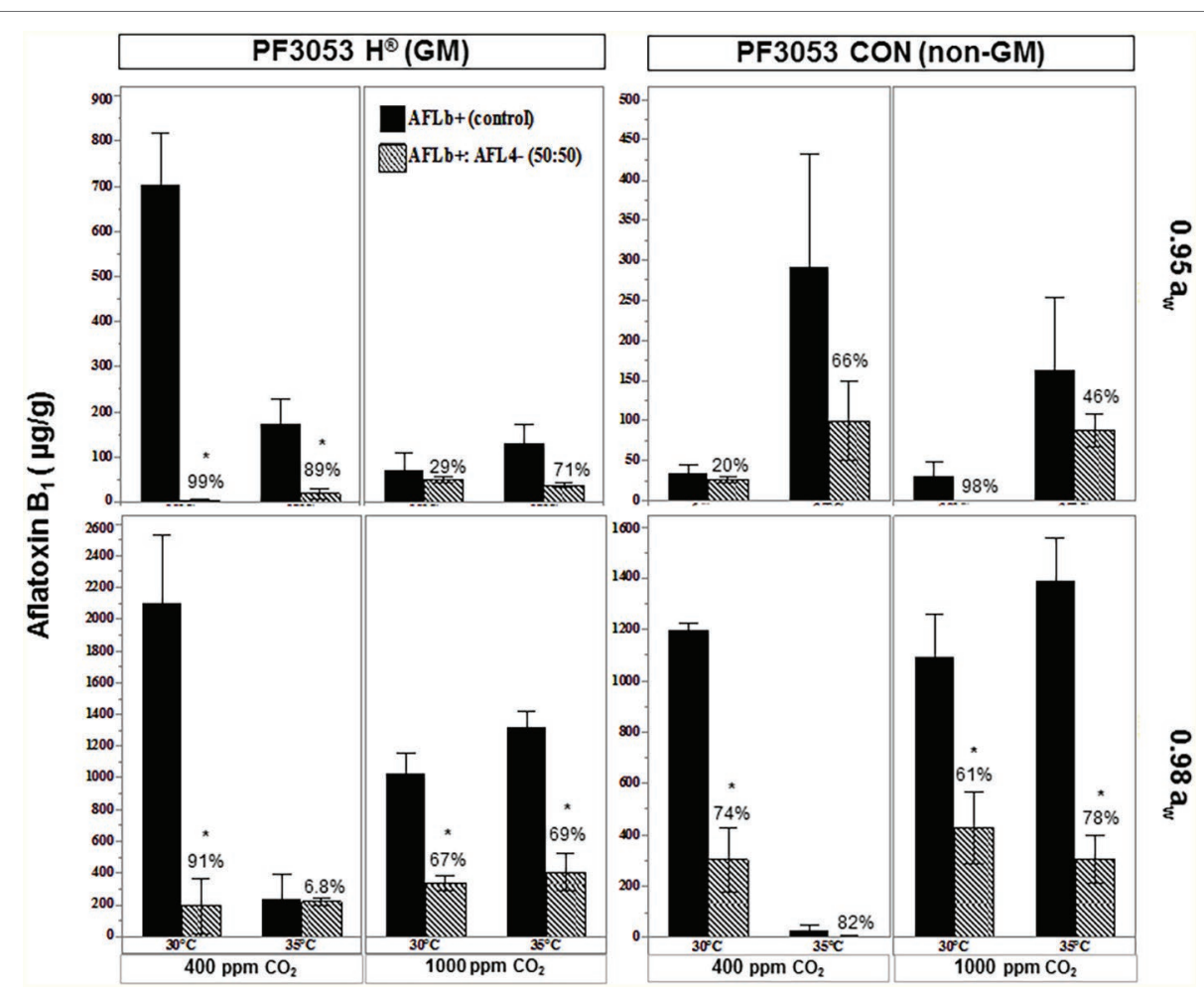

FIGURE 7 | Effect of temperature $\left(30,35^{\circ} \mathrm{C}\right), \mathrm{CO}_{2}(400,1,000 \mathrm{ppm})$, and water activity $\left(\mathrm{a}_{\mathrm{w}}, 0.98,0.95\right)$ on aflatoxin $\mathrm{B}_{1}$ contamination by the Brazilian toxigenic strain $\mathrm{AFLb}^{+}$(control) and biocontrol mixture of $\mathrm{AFLb}^{+}$:AFL4- conidial ratio 50:50 pathogen:antagonist in conventional (P30F53 CON) and isogenic GM (P30F53 H囚) stored maize kernels. Values above bars represent relative control (\%) of aflatoxin $\mathrm{B}_{1}$; ${ }^{*}$ represent significant reduction $(p<0.05)$ of aflatoxin $\mathrm{B}_{1}$ from the toxigenic control (AFLb+).

biosynthetic genes involved in aflatoxin production. In their study, the aflR expression was decreased by a Streptomyces strain, but aflD expression was unaffected by all the biocontrol strains examined. However, these studies did not include the impact of water availability, which may have affected the relative control achieved. In the study by Al-Saad et al. (2016), the efficacy of bacterial biocontrol strains showed significant efficacy with a decrease in the aflD and aflR relative expression, although this was not always translated into effective phenotypic toxin control. 


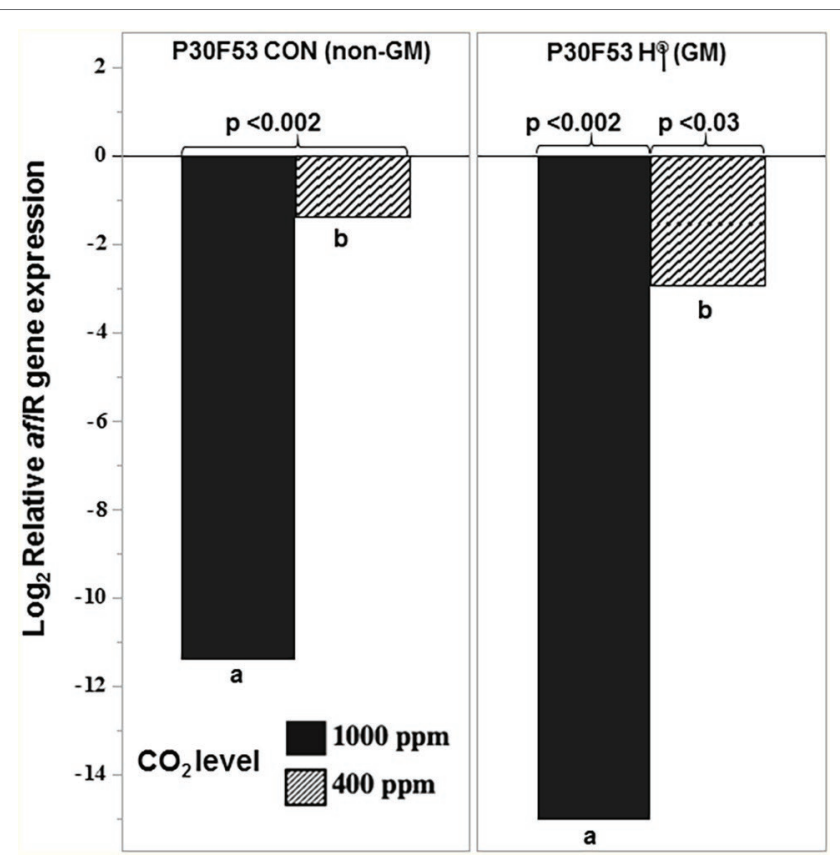

FIGURE 8 | Effect of the non-toxigenic A. flavus strain AFL4- when applied as a conidial inoculum in the ratio of 50:50 with the toxigenic strain $\left(\mathrm{AFL} 4^{-}: \mathrm{AFLb}\right.$ ) on relative expression of the regulatory gene afIR in the conventional (P30F53 CON) and GM (P30F53 H®) stored maize grain at 0.98 $\mathrm{a}_{\mathrm{w}}$ after 10 days at $35^{\circ} \mathrm{C}$ in 400 and $1,000 \mathrm{ppm} \mathrm{CO}$ levels. The expression was normalized for the toxigenic control treatment (AFLb ${ }^{+}$) in each condition. The values of $p$ represent significant differences from the control sample; different letters indicate effects of the $\mathrm{CO}_{2}$ treatment levels $(p<0.05)$.

The non-toxigenic strain AFL4 ${ }^{-}$was able to significantly reduce the $\mathrm{AFB}_{1}$ content in situ when paired with two different toxigenic strains, $\mathrm{AFLb}^{+}$and the type strain NRRL3357 (AFLe $\left.{ }^{+}\right)$ in a 50:50 inoculum ratio. The relative $\mathrm{AFB}_{1}$ control ranged from 58 to $100 \%$ under different $\mathrm{a}_{\mathrm{w}}(0.98$ and 0.95$)$ conditions for up to 20 days storage. Furthermore, the present study has shown for the first time the comparison between impacts of such biocontrol in the reduction of $\mathrm{AFB}_{1}$ in conventional (non-GM) and isogenic GM maize cultivars. The overall $\mathrm{AFB}_{1}$ control indicated that the non-toxigenic strains applied were less resilient in non-GM stored maize cultivars, with the final control achieved being lower than that in the isogenic GM cultivars.

The question is whether this is due to differences in the biochemical composition of non-GM and GM cultivars due to the manipulation of the genes, e.g., the presence of the CrylAb gene. There are few studies, which have examined this. There is a study, which has suggested that CrylAb protein in maize residues had no direct effect on $F$. graminearum and Trichoderma atroviride. However, some corresponding BT/non-BT maize hybrids differed more in composition than that due to the Cry gene alone. However, this may affect the saprophytic growth of such fungi on crop residues (Naef et al., 2006). Changes in free fatty acids (FFA) in maize are an indicator of fungal infections and a deterioration in quality. Thus, fatty acids (FAs) in the maize could play a role in pathogen susceptibility and seed colonization (Dall'Asta et al., 2012). FFAs, especially of linoleic acid levels, partly regulate development, colonization, and mycotoxin production by Aspergillus spp. (Scarpari et al., 2014). Thus, changes in nutritional or environmental factors or both may also influence secondary metabolite production (Magan and Aldred, 2007).

The efficacy of the non-toxigenic strains in controlling $\mathrm{AFB}_{1}$ production was supported by the gene expression of the target structural and regulatory genes ( $a f l \mathrm{D}$, af $l \mathrm{R})$. The results showed that competition in the maize grain niche inhibited the relative expression of both these genes. The correlation with phenotypic $\mathrm{AFB}_{1}$ production showed that the lowered expression of these genes resulted in less toxin after 10 days storage. Previously, Al-Saad et al. (2016) when screening bacterial antagonists as biocontrol agents of toxigenic $A$. flavus strains sometimes found that while relative inhibition of aflD and af $l \mathrm{R}$ expression was evident, sometimes there was concomitant stimulation of $\mathrm{AFB}_{1}$ production. Thus, the resilience of such potential biocontrol strains may well be influenced by water and temperature stress limitations, as well as inoculum ratio $\times$ nutritional parameters to avoid such effects. Recently, Venkatesh and Keller (2019) suggested that there are complex interactions between bacteria and mycotoxigenic fungi and focused on key ecological factors being light, nutrients, and $\mathrm{pH}$. Two probably more important abiotic factors are water availability and temperature. Bacteria require almost freely available water $\left(>0.98-0.99 \mathrm{a}_{\mathrm{w}}\right)$ for growth and have significantly less resilience to water stress than many mycotoxigenic fungi, which are either xerotolerant or xerophilic, the only exceptions being some of the toxigenic Fusaria. However, stored cereals are seldom harvested or stored under wet conditions, and thus, the interactions with bacteria may in fact be relatively limited, although pre-harvest interactions certainly must occur. Thus, the competitive exclusion of toxigenic strains of $A$. flavus is more likely to be successful with non-toxigenic strains or relatively xerotolerant species that may have the temperature and water stress tolerance to compete effectively. Indeed, Kohl et al. (2019) suggested that biocontrol agents use a cascade of mixed mechanisms of action to control plant pathogens, and this needs to be borne in mind when developing biocontrol strategies, including for toxigenic fungal pathogens.

It was noted that the relative gene expression of biosynthetic genes of the toxigenic A. flavus strains in non-GM and isogenic GM-maize was similar for the aflD and aflR at $30^{\circ} \mathrm{C}$ after 10 days storage. However, the phenotypic $\mathrm{AFB}_{1}$ production was different in the two types of cultivars. For example, in the conventional M20-A78 CON cultivar, the relative reduction in $\mathrm{AFB}_{1}$ was lower, and this was supported by the less pronounced reduction in the gene expression of the two genes examined. Furthermore, the $\mathrm{a}_{\mathrm{w}}$ level also had an effect on the relative gene expression when the non-toxigenic strain was applied, under the same storage conditions. Previously, Abdel-Hadi et al. (2010) reported that under water stress levels (e.g., $0.90 \mathrm{a}_{\mathrm{w}}$ ), the aflD expression can 
be increased, although it is optimally expressed at $0.98 \mathrm{a}_{\mathrm{w}}$ on a conducive medium.

It has been shown previously that the ratio of the two regulatory genes aflR and aflS changes with $\mathrm{a}_{\mathrm{w}} \times$ temperature conditions (Abdel-Hadi et al., 2012). The aflR gene encodes for a positive regulator (AFLR), which activates the pathway gene transcription (Chang et al., 1995), whereas the aflS (=aflJ) gene encodes for a protein factor (AFLS), which is involved in the regulation of transcription. These key genes are adjacent to and associated with the expression of a number of structural genes, e.g., aflC, aflD (nor-1), aflM (ver-1), and aflP (omtA; Chang and Hua, 2007). The capacity for disrupting the functioning of either or both of these two genes (aflS, aflR) perhaps by competition from non-toxigenic strains can reduce or completely inhibit aflatoxin production (Meyers et al., 1998; Yu et al., 2004).

This study has explored the effects of elevated $\mathrm{CO}_{2}$ and temperature on potential for control by non-toxigenic fungi, both pre- and post-harvest with both non-GM and GM cultivars. Pre-harvest results suggest that the non-toxigenic strain used $\left(\mathrm{MEX02}^{-}\right)$was not as resilient under elevated climate change interacting factors with no effective control of $\mathrm{AFB}_{1}$ production in maize cobs of the dent stage. The post-harvest studies were able to examine the relative efficacy of the non-toxigenic strain $\left(\mathrm{AFL}^{-}{ }^{-}\right.$) on control of $\mathrm{AFB}_{1}$ in related non-GM and isogenic GM cultivars for the first time. The effect of increasing $\mathrm{CO}_{2}$ at 30 and $35^{\circ} \mathrm{C}$ varied depending on the type of maize used (conventional or GM). This was the first attempt to analyze whether using these two types of cultivars under climate-related abiotic factors can cause differences in $\mathrm{AFB}_{1}$ production and the level of control achieved when using non-toxigenic biocontrol strains.

The action of the non-toxigenic A. flavus strain (AFL4 ${ }^{-}$) as a biocontrol agent was significant in the elevated $\mathrm{CO}_{2}$ treatments, although the overall efficacy was lower than in non-climate change abiotic conditions. The use of the GM cultivar (P30F53 $\mathrm{H}^{\circledR}$ ) showed better results in terms of relative biocontrol under abiotic stress $\left(\begin{array}{lll}0.95 & \mathrm{a}_{\mathrm{w}}\end{array}\right)$ and increased $\mathrm{CO}_{2}$.

There are limited previous studies to examine the effect of three-way interacting abiotic factors of elevated temperature $\times$ elevated $\mathrm{CO}_{2} \times$ drought stress effects on biocontrol of mycotoxin production (Verheecke-Vaessen et al., 2019). Previously, three-way interacting climate change abiotic factors were shown to stimulated $\mathrm{AFB}_{1}$ production by the type strain of $A$. flavus (NRRL strain) both in vitro and in stored maize grain under increased temperature $\left(30\right.$ vs. $\left.34-37^{\circ} \mathrm{C}\right)$, 350 vs. $650 / 1,000 \mathrm{ppm}, \mathrm{CO}_{2}$, and different $\mathrm{a}_{\mathrm{w}}$ stress levels (Medina et al., 2015, 2017b). While growth of A. flavus was relatively unaffected, expression of key genes such as the aflR and aflD was significantly increased and translated into a stimulation of $\mathrm{AFB}_{1}$ production. Indeed, Vaughan et al. (2014) demonstrated that elevated $\mathrm{CO}_{2}(800 \mu \mathrm{mol}$ $\mathrm{CO}_{2} \mathrm{~mol}^{-1}$ air) enhanced maize susceptibility to F. verticillioides infection, but the increase in fungal biomass did not result in higher $\mathrm{FB}_{1}$ toxin levels. Although subsequent studies suggested that there was an interaction between drought stress and elevated $\mathrm{CO}_{2}$, which increased $\mathrm{FB}_{1}$ production (Vaughan et al., 2016).

More recently, Gilbert et al. (2018) using RNA-Sequencing demonstrated that $\mathrm{AFB}_{1}$ production in stored maize grain was altered by $\mathrm{a}_{\mathrm{w}} \times$ temperature $\times$ elevated $\mathrm{CO}_{2}$. Also, several genes involved in the biosynthesis of secondary metabolites exhibit different responses to $\mathrm{a}_{\mathrm{w}}$ or temperature stress depending on the atmospheric $\mathrm{CO}_{2}$ content. At $37^{\circ} \mathrm{C}$ and $1,000 \mathrm{ppm} \mathrm{CO}_{2}$, the transcription factor aflR was decreased. After 10 days incubation, the expression of biosynthetic genes in maize stored at $30^{\circ} \mathrm{C}$ generally decreased. However, the effects of high $\mathrm{CO}_{2}$ $(1,000 \mathrm{ppm})$ and water stress $\left(0.91 \mathrm{a}_{\mathrm{w}}\right)$ showed decreased values, possibly in response to elevated $\mathrm{AFB}_{1}$ levels (Gilbert et al., 2018).

Other imposed chemical stresses may also result in physiological impacts on toxigenic fungi such as A. flavus. Recent studies by Hanano et al. (2019) have shown that the most toxic congener of dioxin, the 2,3,7,8-tetrachlorinated dibenzo-p-dioxin, reduced growth but stimulated both conidial sporulation and $\mathrm{AFB}_{1}$ production supported by levels of biosynthetic gene expression. Indeed, such exposure to chemical stress was shown to increase the production of superoxide dismutase and catalase. Of particular interest was the activity of caleosin/peroxygenase enzyme, which was activated in the presence of such recalcitrant compounds. This suggests that exposure to elevated levels of atmospheric particulates and gaseous stresses such as $\mathrm{CO}_{2}$ and interaction with elevated temperatures may impact on physiological functioning of $A$. flavus and influence the toxin contamination levels.

\section{CONCLUSIONS}

This study has shown that the relationship between pre-harvest ripening stage of maize cobs and their inherent water availability will influence both colonization and $\mathrm{AFB}_{1}$ production by toxigenic A. flavus strains and also influence the potential for effective control of toxin contamination. Thus, by using a 50:50 ratio of BCA:pathogen composition, the efficacy of the non-toxigenic strain was more effective at the R3 and R4 ripening stages, supported by the downregulation of the two toxin genes $(a f D$, aflR) relative expression, accompanied by a significant reduction in $\mathrm{AFB}_{1}$ contamination. At the dent stage, perhaps a higher inoculum of the non-toxigenic strain is necessary for effective control.

Post-harvest, biocontrol of $\mathrm{AFB}_{1}$ production in non-GM and GM cultivars was affected by interacting variables: type of cultivar, $T^{\circ} \mathrm{C}, \mathrm{CO}_{2}$ levels, and water availability conditions. These interactions may also significantly affect BCA resilience and relative action. This study suggests that in GM cultivars, the relative control was slightly more effective than in the equivalent isogenic non-GM maize cultivars post-harvest. The resilience of the non-toxigenic strains appeared to vary between these. Overall, it is very important to include resilience to climate-related abiotic factors to ensure that 
the identified strains of non-toxigenic strains and indeed other biocontrol candidates have the necessary ecological competence to compete effectively and reduce toxin contamination, whether the approach is for controlling preor post-harvest. Formulation approaches for such biocontrol agents may also play an important role in conserving resilience under a range of interacting abiotic conditions in the maize agroecosystem.

\section{DATA AVAILABILITY STATEMENT}

All the data sets are deposited with Cranfield University via the senior author and can be openly accessed via him.

\section{REFERENCES}

Abbas, H., Weaver, M. A., Horn, B. W., Carbone, I., Monacell, J. T., and Shier, W. T. (2011). Selection of Aspergillus flavus isolates for biological control of aflatoxin in corn. Toxin Rev. 30, 59-70. doi: 10.3109/15569543.2011.591539

Abdel-Hadi, A., Carter, D., and Magan, N. (2010). Temporal monitoring of the nor-1 (aflD) gene of Aspergillus flavus in relation to aflatoxin $\mathrm{B}_{1}$ production during storage of peanuts under different environmental conditions. J. Appl. Microbiol. 109, 1914-1922. doi: 10.1111/j.1365-2672.2010.04820.x

Abdel-Hadi, A., Schmidt-Heydt, M., Parra, R., Geisen, R., and Magan, N. (2012). A systems approach to model the relationship between aflatoxin gene cluster expression, environmental factors, growth and toxin production by Aspergillus flavus. J. R. Soc. Interface 9, 757-767. doi: 10.1098/ rsif.2011.0482

Al-Saad, L., Al-Badran, A. I., Al-Jumayli, S. A., Magan, N., and Rodriguez, A. (2016). Impact of bacterial biocontrol agents on aflatoxin biosynthetic genes, aflD and aflR expression, and phenotypic aflatoxin $B_{1}$ production by Aspergillus flavus under different environmental and nutritional regimes. Int. J. Food Microbiol. 217, 123-129. doi: 10.1016/j.ijfoodmicro.2015.10.016

Bandyopadhyay, R., Ortega-Beltran, A., Akande, A., Mutegi, C., Atehnkeng, J., Kaptoge, L., et al. (2016). Biological control of aflatoxins in Africa: current status and potential challenges in the face of climate change. World Mycotoxin J. 9, 771-789. doi: 10.3920/WMJ2016.2130

Battilani, P., Toscano, P., Van der Fels-Klerx, H. J., Moretti, A., Camardo Leggieri, A. M., Brera, C., et al. (2016). Aflatoxin B1 contamination in maize in Europe increases due to climate change. Sci. Rep. 6. doi: 10.1038/srep24328

Callicott, K. A., and Cotty, P. J. (2015). Method for monitoring deletions in the aflatoxin biosynthesis gene cluster of Aspergillus flavus with multiplex PCR. Lett. Appl. Microbiol. 60, 60-65. doi: 10.1111/lam.12337

Chan, Y., and Walmsley, R. P. (1997). Learning and understanding the KruskalWallis one-way analysis-of-variance-by-ranks test for differences among three or more independent groups. Phys. Ther. 77, 1755-1762. doi: 10.1093/ptj/77.12.1755

Chang, P.-K., Ehrlich, K. C., Yu, J., Bhatnagar, D., and Cleveland, T. E. (1995). Increased expression of Aspergillus parasiticus aflR, encoding a sequence-specific DNA-binding protein, relieves nitrate inhibition of aflatoxin biosynthesis. Appl. Environ. Microbiol. 61, 2372-2377.

Chang, P.-K., and Hua, S.-S. T. (2007). Nonaflatoxigenic Aspergillus flavus TX9-8 competitively prevents aflatoxin accumulation by $A$. flavus isolates of large and small sclerotial morphotypes. Int. J. Food Microbiol. 114, 275-279. doi: 10.1016/j.ijfoodmicro.2006.09.017

Cotty, P. J. (1994). Influence of field application of an atoxigenic strain of Aspergillus flavus on the populations of A. flavus infecting cotton bolls and on the aflatoxin content of cottonseed. Phytopathology 84, 1270-1277. doi: 10.1094/Phyto-84-1270

Dall'Asta, C., Falavigna, C., Galaverna, G., and Battilani, P. (2012). Role of maize hybrids and their chemical composition in Fusarium infection and fumonisin production. J. Agric. Food Chem. 60, 3800-3808. doi: 10.1021/jf300250z

Dolezal, A. L., Shu, X., OBrian, G. R., Nielsen, D. M., Woloshuk, C. P., Boston, R. S., et al. (2014). Aspergillus flavus infection induces transcriptional and

\section{AUTHOR CONTRIBUTIONS}

AG and AR-S carried out the research work. EG-C and CV-V assisted with molecular work and quantification of toxins. $\mathrm{AM}$ and NM supervised the research and drafted the manuscript.

\section{FUNDING}

AG is grateful to the Brazilian Government through its CAPES scheme for financial support for her $\mathrm{PhD}$, and $\mathrm{AR}-\mathrm{S}$ is grateful to CONACyt, Mexico, for support for her $\mathrm{PhD}$ scholarship. Partial funding was from the EU Horizon 2020 research and innovation programme under grant agreement No 678012.

physical changes in developing maize kernels. Front. Microbiol. 5, 1-10. doi: $10.3389 /$ fmicb.2014.00384

Gilbert, M. K., Medina, A., Mack, B. M., Lebar, M., Rodriguez, A., Bhatnagar, D., et al. (2018). Carbon dioxide mediates the response to temperature and water activity levels in Aspergillus flavus during infection of maize kernels. Toxins 10:5. doi: $10.3390 /$ toxins 10010005

Giorni, P., Bertuzzi, T., and Battilani, P. (2019). Impact of fungi co-occurrence on mycotoxin contamination in maize during the growing season. Front. Microbiol. 10:1265. doi: 10.3389/fmicb.2019.01265

Hanano, A., Almousally, I., and Shaban, M. (2019). Exposure of Aspergillus flavus NRRL 3357 to the environmental toxin, 2,3,7,8-tetrachlorinated dibenzop-dioxin, results in a hyper-aflatoxigenic phenotype: a possible role for coleosin/ peroxygenase (AfPXC). Front. Microbiol. 10:2338. doi: 10.3389/fmicb.2019.02338

Kagot, V., Okoth, S., De Boevre, M., and De Saeger, S. (2019). Biocontrol of Aspergillus and Fusarium mycotoxins in Africa: benefits and limitations. Toxins 11:109. doi: 10.3390/toxins11020109

Kohl, J., Kolnarr, R., and Ravensberg, W. J. (2019). Mode of action of biocontrol agents against plant dieases: relevance beyond efficacy. Front. Microbiol 10:845. doi: $10.3389 /$ pls.019.00945

Livak, K. J., and Schmittgen, T. D. (2001). Analysis of relative gene expression data using real-time quantitative PCR and the 2(-delta delta $\mathrm{C}(\mathrm{T})$ ) method. Methods 25, 402-408. doi: 10.1006/meth.2001.1262

Lyn, M. E., Abbas, H. K., Zablotowicz, R. M., and Johnson, B. J. (2009). Delivery systems for biological control agents to manage aflatoxin contamination of pre-harvest maize. Food Addit. Contam., Part A 26, 381-387. doi: $10.1080 / 02652030802441521$

Magan, N., and Aldred, D. (2007). "Why to fungi produce mycotoxins?" in Food mycology: a multifaceted approach to fungi and food. eds. J. Dijksterhuis and R. A. Samson (Boca Raton, FL: Taylor \& Francis), 121-133.

Marcon Gasperini, A. (2019). Fungal diversity, pest damage and biocontrol of aflatoxins in GM and conventional Brazilian maize cultivars under existing and future climate change scenarios. $\mathrm{PhD}$ thesis. Cranfield University.

Mauro, A., Garcia-Cela, E., Pietri, A., Cotty, P. J., and Battilani, P. (2018). Biological control products for aflatoxin prevention in Italy: commercial field evaluation of atoxigenic Aspergillus flavus active ingredients. Toxins 10:30. doi: 10.3390/toxins 10010030

Medina, A., Akbar, A., Baazeem, A., Rodriguez, A., and Magan, N. (2017b). Climate change, food security and mycotoxins: do we know enough? Fungal Biol. Rev. 31, 143-154. doi: 10.1016/j.fbr.2017.04.002

Medina, A., Mohale, S., Samsudin, N. I. P., Rodriguez-Sixtos, A., Rodriguez, A., and Magan, N. (2017a). Biocontrol of mycotoxins: dynamics and mechanisms of action. Curr. Opin. Food Sci. 17, 41-48. doi: 10.1016/j. cofs.2017.09.008

Medina, A., Rodríguez, A., Sultan, Y., and Magan, N. (2015). Climate change factors and A. flavus: effects on gene expression, growth and aflatoxin production. World Mycotoxin J. 8, 171-179. doi: 10.3920/WMJ2014.1726

Meyers, D. M., Obrian, G., Du, W. L., Bhatnagar, D., and Payne, G. A. (1998). Characterization of aflJ, a gene required for conversion of pathway intermediates to aflatoxin. Appl. Environ. Microbiol. 64, 3713-3717. 
Mohale, S., Medina, A., and Magan, N. (2013). Effect of environmental factors on in vitro and in situ interactions between atoxigenic and toxigenic $A$. flavus strains and control of aflatoxin contamination of maize. Biocontrol Sci. Tech. 23, 776-793. doi: 10.1080/09583157.2013.794895

Naef, A., Zesiger, T., and Défago, G. (2006). Impact of transgenic Bt maize residues on the mycotoxigenic plant pathogen Fusarium graminearum and the biocontrol agent Trichoderma atroviride. J. Environ. Qual. 35, 1001-1009. doi: $10.2134 /$ jeq2005.0334

Reese, B. N., Payne, G., Nielsen, D. M., and Woloshuk, C. P. (2011). Gene expression profile and response to maize kernels by Aspergillus flavus. Phytopathology 101, 797-804. doi: 10.1094/PHYTO-09-10-0261

Rodríguez-Sixtos, A. (2017). Fungal interactions and control of aflatoxins in maize, pre-and post-harvest under different climate change scenarios. $\mathrm{PhD}$ thesis. Cranfield University.

Samsudin, N. I. P., and Magan, N. (2016). Efficacy of potential biocontrol agent thresholds for control of Fusarium verticillioides and fumonisin $B_{1}$ production under different environmental conditions on maize-based medium. World Mycotoxin J. 9, 205-213. doi: 10.3920/WMJ2015.1886

Samsudin, N. I. P., Rodriguez, A., Medina, A., and Magan, N. (2017). Efficacy of a fungal and bacterial antagonist for controlling growth, FUM1 gene expression and fumonisin $\mathrm{B}_{1}$ by Fusarium verticillioides on maize cobs of different ripening stages. Int. J. Food Microbiol. 246, 72-79. doi: 10.1016/j. ijfoodmicro.2017.02.004

SAS Institute (2018). Statistical analysis system 9 for windows.

Scarpari, M., Punelli, M., Scala, V., Zaccaria, M., Nobili, C., Ludovici, M., et al. (2014). Lipids in Aspergillus flavus-maize interactio. Front. Microbiol. 5:74. doi: $10.3389 /$ fmicb.2014.00074

Schmidt-Heydt, M., Magan, N., and Geisen, R. (2008). Stress induction of mycotoxin biosynthesis genes by abiotic factors. FEMS Microbiol. Lett. 284, 142-149. doi: 10.1111/j.1574-6968.2008.01182.x

Vaughan, M. M., Huffaker, A., Schmelz, E. A., Dafoe, N. J., Christensen, S. A., McAuslane, H. J., et al. (2016). Interactive effects of elevated $\left[\mathrm{CO}_{2}\right]$ and drought on the maize phytochemical defence response against mycotoxigenic Fusarium verticillioides. PLoS One 11:e0159270. doi: 10.1371/journal. pone. 0159270
Vaughan, M. M., Huffaker, A., Schmelz, E. A., Dafoe, N. J., Christensen, S., Sims, J., et al. (2014). Effects of elevated $\left[\mathrm{CO}_{2}\right]$ on maize defence against mycotoxigenic Fusarium verticillioides. Plant Cell Environ. 37, 2691-2706. doi: $10.1111 /$ pce. 12337

Venkatesh, N., and Keller, N. P. (2019). Mycotoxins in conversation with bacteria and fungi. Front. Microbiol. 10:403. doi: 10.3389/fmicb.2019.00403

Verheecke, C., Liboz, T., Anson, P., Zhu, Y., and Mathieu, F. (2015). Streptomyces-Aspergillus flavus interactions: impact on aflatoxin B accumulation. Food Addit. Contam., Part A 32, 572-576. doi: 10.1080/ 19440049.2014.1003336

Verheecke-Vaessen, C., Diez-Gutierrez, L., Renaud, J., Sumarah, M., Medina, A., and Magan, N. (2019). Interacting climate change environmental factors effects on Fusarium langsethiae growth, expression of TRI genes and T-2/HT-2 mycotoxin production on oat-based media and in stored oats. Fungal Biol. 123, 617-623. doi: 10.1016/j.funbio.2019.04.008

Weaver, M. A., Abbas, H. K., Jin, X., and Elliott, B. (2016). Efficacy of waterdispersible formulations of biological control strains of Aspergillus flavus for aflatoxin management in corn. Food Addit. Contam. Part A 33, 346-351. doi: 10.1080/19440049.2015.1129071

Yu, J., Chang, P.-K., Ehrlich, K. C., Cary, J. W., Bhatnagar, D., Cleveland, T. E., et al. (2004). Clustered pathway genes in aflatoxin biosynthesis Appl. Environ. Microbiol. 70, 1253-1262. doi: 10.1128/AEM.70.3.12531262.2004

Conflict of Interest: The authors declare that the research was conducted in the absence of any commercial or financial relationships that could be construed as a potential conflict of interest.

Copyright (C) 2019 Gasperini, Rodriguez-Sixtos, Verheecke-Vaessen, Garcia-Cela, Medina and Magan. This is an open-access article distributed under the terms of the Creative Commons Attribution License (CC BY). The use, distribution or reproduction in other forums is permitted, provided the original author(s) and the copyright owner(s) are credited and that the original publication in this journal is cited, in accordance with accepted academic practice. No use, distribution or reproduction is permitted which does not comply with these terms. 